\title{
El asno del Pensé Que en la Filosofía cortesana de Alonso de Barros
}

\author{
Ernesto Lucero Sánchez
}

Universidad de Jaén

ernesto.lu00@gmail.com

Recepción: 03/01/2019, Aceptación: 13/05/2019, Publicación: 04/12/2019

\section{Resumen}

La Filosofía cortesana de Alonso de Barros contiene las reglas precisas para empezar una partida en una versión del juego de la oca que representa en el tablero la corte de finales del siglo xvi. El itinerario del jugador es también el camino que debe seguir el pretensor para obtener favores y prebendas, para mejorar su estatus en la casa final de la Palma de la Victoria. Aunque no lo aparenta por su naturaleza lúdica, el autor concibió el conjunto de libro y pintura como una reivindicación del valor del trabajo. El emblema del Pensé Que, que ocupa una de las casas del tablero y cuyo origen valoramos en este artículo, se opone a la Diligencia debida para lograr cualquier objetivo cortesano.

Palabras clave

Alonso de Barros; Filosofía cortesana; Penseque; Pensé Que; ocio; ociosidad; trabajo; juego de la oca; corte

\begin{abstract}
The donkey named "I thoughtthat" in Filosofía cortesana, by Alonso de Barros

Alonso de Barros' Filosofía cortesana includes the precise rules to begin a game in a version of the Game of the Goose that represents the court of the late 16th century on the board. The player's itinerary is also the way to be followed by a pretender in order to get favours and prebends and improve his status in the final house of la Palma de la Victoria. Although it does not seem so, due to its ludic nature, the author understood the set of book and painting as a recognition of the value of work. The emblem of Pensé Que (I thought that), which occupies one of the houses of the board and whose origin is analysed in this article, is against the diligence required to achieve any courtly objective.
\end{abstract}

\section{Keywords}

Alonso de Barros; Filosofía cortesana; Pensé Que (I thoughtthat); leisure; idleness; work; Game of Goose; court 
¿Qué es la cosa que sin ella muy mejor la conoçemos y quando en nos la tenemos no sabemos conoçella; y al tiempo que'stá perfecta en aquel que la posee todo el mundo se la vee y dél mesmo está secreta? ${ }^{1}$

Alonso de Barros dio a la imprenta en 1587 un entretenimiento cortesano basado en el juego de la oca donde conjuga la imagen simbólica y el texto en la creación de un manual de ciencia áulica para pretensores, que reivindica desde el tablero el valor primordial del trabajo para mejorar de estado. No solo se juega en la corte. La ontología de la propia corte es juego, ${ }^{2}$ como bien sabe Alonso de Barros. Un juego en que la competencia resulta despiadada. De ahí que nuestro autor comprenda la necesidad de aprehender los engranajes que articulan las relaciones personales y la política y su trascendencia moral. El resultado es este código de conducta basado en el esfuerzo personal titulado Filosofía cortesana.

El texto de la obra viene acompañado por una pintura en «un pliego grande» que contiene un itinerario espiral dividido en 63 casas, como en el juego de que procede, varias de las cuales llevan un pequeño emblema que representa alguno de los avatares o momentos de la carrera cortesana por lograr la Palma de la Vitoria, situada en la casilla final, como los peligros de la Falsa Amistad, la temida Mudanza de Ministros o la más temida Muerte del Valedor, que obliga al jugador a comenzar las diligencias para conseguir su aspiración. Varias de las casas de la pintura en que se distribuyen las enseñanzas se polarizan en un eje que opone actividad a pasividad. Las que se orientan a producir una actitud activa del sujeto reciben una recompensa, mientras que las que tienden a la inacción, como el Qué Dirán o

1. Se trata del enigma de la Necedad contenido en el Hospital de necios, de Hurtado de Toledo (Gamba 2013: 1016). Existen varios enigmas con este motivo que hacen hincapié en que el necio ignora su condición.

2. «La vida de la corte, dice La Bruyère, 'es un juego grave y melancólico, que se juega del modo siguiente: es necesario ordenar las piezas y las baterías, tener un objetivo, inutilizar el del adversario, a veces, arriesgarse y tentar la suerte. Y después de todas estas cavilaciones y medidas uno se encuentra con un jaque que a veces es mate'» (Elias 1988: 574). 
Pobreza, obstan o difieren la consecución de los objetivos. ${ }^{3}$ La contraposición más característica en la Filosofía cortesana atañe a Pensé Que y Diligencia, siendo esta una manifestación particular del Trabajo constante. En estas páginas pretendemos rastrear el origen de la curiosa composición de la casa del Pensé Que, donde se asocian a ese título la figura de un asno echado y el sentido básico de descuido u holgazanería; también intentaremos explicar otras conexiones semánticas tanto de la imagen como del nombre y su fortuna posterior.

Lo primero que debemos apuntar al inicio de este recorrido concierne al significado que Alonso de Barros otorga a la representación del Pensé Que. La novedad de su planteamiento consiste en invertir la concepción que habitualmente se ofrecía del asno como animal vinculado al trabajo no solo en la vida, sino también en la literatura y en la iconología tradicional. En esa línea, la figura del asno se opone aquí al sentido clave que confiere a otro animal de características semejantes, como es el buey, emblema del Trabajo e imagen esencial en el tablero, ${ }^{4}$ ya que sustituye a la oca como animal benéfico y como casilla mecánica que se reitera en diversos lugares de la espiral. Aunque no se trata de una oposición desconocida, nunca se debió a una supuesta indolencia del asno que se pudiera contraponer a la capacidad de padecer las penalidades del trabajo del buey. De hecho, lo previsible es que compartan una misma interpretación. Se puede rastrear en esta dirección su paradigmática presencia en la literatura didáctica de tipo alegórico, que toca la oposición polar de ocio y trabajo de manera explícita. Por ejemplo, en uno de los libros que atesoraba Barros en su biblioteca, el Apólogo de la ociosidad y el trabajo, de Luis Mexía, glosado y moralizado por Francisco Cervantes de Salazar se constata este enfoque análogo de ambos animales. ${ }^{5}$ Así, el planteamiento de Cervantes de Salazar a la hora de explorar el argumento de la obra de Mexía resulta meridianamente claro:

La intención del autor fue, debaxo de sabrosa especie de poesía, filosóficamente tratar los grandes provechos del trabajo y por el contrario los daños de la ociosidad; y para esto finge que en Grecia había una regalada señora llamada Ocia, que es la ociosidad, la cual en su compañía traía a madona Fraude, que es el engaño, y la Hipocresía y la Pereza y la Ignorancia, las cuales servían a esta señora por huir del trabajo, tan enemigo de los ignorantes. ${ }^{6}$

Labricio pretende casarse con Dońa Ocia, quien, no obstante, rechaza los obsequios que este le ofrece por su desposorio, todos relacionados con las vir-

3. El Qué Dirán, que supone una inmovilidad que ata al hombre no ya al ocio, sino a la frustración del logro no obtenido en la Corte ante el temor de volver manivacío a su lugar de procedencia y afrontar la vergüenza del fracaso; también la Pobreza, resultado quizá de no controlar la propia liberalidad en el empeño cortesano o producto acaso de los vicios asociados a la ociosidad pródiga.

4. Lucero (2019).

5. Dadson (1987: 40). También se ha publicado este trabajo en Dadson (1998).

6. Ver «Argumento y moralidad de la obra» (Cervantes de Salazar 2012: 91). 
tudes del trabajo, y deshace el compromiso. Gracias a eso, Labricio contraerá nupcias con Diligencia, un personaje mucho más afín a su naturaleza. Del fragmento nos atrae no solo el evidente contenido moral de las alegorías ${ }^{7}$ sino que entre los presentes de Labricio se cuentan — decíamos- los animales que nos interesan, ambos asociados al trabajo. Nos vamos a ceñir ahora, dentro del propósito que nos hemos marcado, al pasaje relativo al asnillo, pero se ensalza igualmente al buey:

Tráigote, ansí mismo, un asnillo que vale más que el de Apuleyo, aunque el otro decía que era de oro; este, señora, aunque paresce vil animal y no digno de ser metido en cuenta de estima, pero no por eso deja de ser muy provechoso para el servicio de la casa, familia y república. Más te digo, que ninguno por alto que sea en linage, estado ni condición debe despreciar los baxos, ni tener en poco los que al mundo parescen abyectos, porque, si bien se mira, estos muchas vezes son las basas sobre que los mayores se firman. Sobre los hombros destos los más altos reyes y emperadores se recobdan, sobre las cabeças destos los otros se suben para después tomar vuelo sin contradición. Estos son grande parte de alivio de sus trabajos, sustento de sus personas, socorro de sus necessidades. Los que a estos no saben conservar, menospreciando su baxeza y simplicidad, muchas vezes quieren ir adelante y se hallan atrás. (Cervantes de Salazar 2012: 108-109)

El animal se vincula, pues, de manera palmaria al trabajo, y esa parece ser la razón de que aparezca en el tablero de Barros, que opone el holgazán del Pensé Que a la Diligencia. Holgazán, suponemos, porque está tumbado.

Y la tibieza confiada para el dejarlo todo es escudo de holgazanes, y más de los que son tales que, no haciendo ellos diligencia en sus negocios, piensan que otros las harán. Por esto, y porque es muy de dichosos el descuidarse, se pinta a cincuenta y cinco casas la del Pensé Que, figurado por un asno echado, por la semejanza que con él tiene el que dice "¿quién pensara?», y no lo previene. De los cuales es cierto lo que su letra dice: Del Pensé Que huye ventura, / y la que tiene no dura. Mándasele al tal descuidado que torne y haga Diligencia. (Barros 1987: 28r-29r)

7. Reténgase la presencia simultánea de la Ignorancia y de la Pereza para lo que se verá en estas páginas, así como la noción de que el trabajo es enemigo de los ignorantes. 


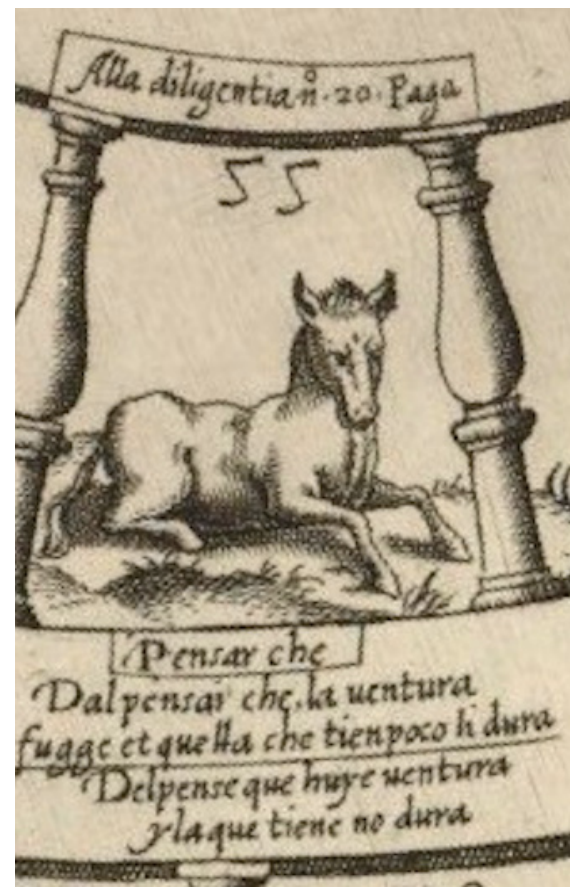

Figura 1

Pensé Que (casa núm. 55). Filosofía cortesana. (C) The Trustees of the British Museum: AN137041.

Sin embargo, no siempre ha bastado la postura del animal para decretar que su significado simbólico varíe en un sentido o en otro, como demuestra el caso del buey echado sobre el heno con que Juan de Borja ilustra el merecido descanso, que se halla muy lejos de cualquier connotación peyorativa. ${ }^{8}$ La acidia, de hecho, no es comúnmente representada en los emblemas por el asno ni tiene este condición de perezoso en las fábulas de Esopo, ${ }^{9}$ si bien parece formar parte de los atributos que se predican de manera esporádica del cuadrúpedo, a menudo solo de manera incidental en el relato. ${ }^{10}$ El único rastro en ese sentido que hemos hallado se en-

8. El lema de la empresa es "Quies bona». El comentario hace mención expresa de la vejez. Ver Bernat y Cull (1999: núm. 259).

9. Aunque en alguna intenta aligerar el exceso de carga, no parece la pereza el objeto de las fábulas esópicas en que participa (cf. «El burro y la mula» o «El burro que acarreaba sal», en Esopo 1978: 121-122).

10. Así se deduce de la lectura del peculiar libro de Manuel Lozano Pérez Ramajo, El asno ilustrado, o sea, la apología del asno, que en centenares de páginas sobre el rucio solo menciona cuatro veces la 
cuentra en El asno de oro, de Apuleyo, aunque las escasas asociaciones del adjetivo perezoso al animal distan de confluir con un arquetipo, ya que las circunstancias determinan el uso. ${ }^{11}$ Una lectura de esa entidad, aunque única, pudiera ser bastante para esbozar un rasgo de carácter como este en la mentalidad del autor, quien postulamos que conoció el libro.

Collar de Cáceres asume esta concepción explícita de Barros y ha hallado para corroborarla la bella imagen de Guido Reni titulada "Acidia vestita di nero", que supone basada en la Iconología de Ripa, cuya primera edición es posterior a la Filosofía cortesana. La duda que nos suscita, a pesar de las evidentes concomitancias entre estas imágenes, concierne a si la pereza es la mujer — como pensamos y como se deduce de la figura de Ripa-, el asno echado — como en Barros- o, en su caso, el conjunto; nos preguntamos si el asno tumbado, en definitiva, es esencial o accidental en el emblema. ${ }^{12}$

palabra 'pereza' para refutarla, como corresponde al sentido de la obra. Las referencias a su presunta holgazanería se han perdido en la definición actual del $D L E$, pero figuraban en una versión anterior. La edición de Madrid (Joaquín Ibarra, 1770) contraponía asno y buey, como el tablero de Barros: «El buey es fuerte y robusto, el asno perezoso». Esta afirmación desaparece en la edición en un solo tomo del año 1773 de la entrada en cuestión. La diferencia de asno y buey, que no oposición, aparece ya claramente planteada en Deuteronomio $(22,10)$, sin necesidad de otras connotaciones. El Hospital de necios, en cambio, recuerda el texto bíblico acentuando su polaridad, con estos versos: "De la escriptura me acuerdo / que diçe que en un arado / no sea el asno y buey atado, / ni menos el neçio y cuerdo / deven comer un bocado» [fol. 125r, vv. 541-545] (Gamba 2013: 990).

11. Dado que el empleo del término en la traducción se puede discutir, hemos utilizado la edición atribuida a Diego López de Cortegana, Sevilla, c. 1513, al ser la que pudo haber conocido Barros (sobre esta edición, ver Escobar 2002, 2011). En ella, después de anotar las ocurrencias textuales, hemos observado que tres se enmarcan en un contexto de castigo del animal (por la fuga de la doncella en el libro 6; hablando de los beneficios de la castración «no solamente de estos asnos perezosos», en el libro 7; tras morder la mano a quien le revisaba los dientes, entre otros calificativos del pregonero que pretende venderlo) y la que resta no se piensa: se trata del intento vano de recuperar el burro del hortelano a quien se lo acaba de robar el caballero. En el último episodio donde se le tilda de perezoso, prima el epíteto de tragón o comilón. Nunca podemos, para finalizar, abstraernos de que la conducta corresponde a Lucio, transformado. Para terminar, las ediciones ilustradas de ese periodo no muestran nunca al asno echado.

12. La vieja está sentada, tiene un paño negro sobre la cabeza y sostiene un pez en la mano. Collar de Cáceres (2009: 97-98) añade: «Puede además llevar según Ripa una cuerda, porque la pereza ata y vence a los hombres, o una tortuga, pero también cabe mostrarla como una 'mujer yacente en tierra, a cuyo lado se verá un asno también yacente', animal que entre los Egipcios, dice, mostraba el alejamiento de la mente de las cosas sagradas y la ocupación en pensamientos viles y blasfemos según afirmaba Pierio Valeriano». La referencia a la cuerda procede del libro duodécimo de Pierio Valeriano, que concede como primer valor al asno la ignorancia, no la pereza. Hay un antecedente en Alciato, que representa al soguero que va trenzando una cuerda de esparto que su asna va comiendo, donde la pereza se aproxima a la prodigalidad de la mujer: «Así la gastadora mujer gasta, / cuanto el marido acaudalar no abasta» (Bernat y Cull 1999: núm. 1182; también en Covarrubias 1674), cuya historia se atribuye remotamente a Pausanias en Pierio Valeriano, Hieroglificos. También aparece citado el «perezoso espartero Ocnos» en Lozano (1837: 211), donde se recuerda que la piedra inferior del molino «se llama en griego 'asno' por ser tarda o por no moverse». Así se recoge en Covarrubias. Hoy se conoce como «solera» o «durmiente», mientras que la superior se denomina «volandera» o 
Nada de lo visto hasta aquí aclara, en suma, el origen del curioso nombre de la casa 55, el Pensé Que, cuyo estudio nos lleva mucho más cerca de elucidar la génesis del emblema que la investigación sobre el carácter del animal, la cual, aunque admite muchos matices en la interpretación, invoca como valores arquetípicos la rudeza o estolidez, su terquedad o rijosidad; el trabajo sufrido, antes que la pereza.

El Pensé Que o Penseque, completamente lexicalizado, es una «voz de necios» ligada a cierta literatura satírica que corre en forma de genealogías o pragmáticas de burlas, vinculadas a personajes alegóricos con una primera intención cómica, no moral, a diferencia de apólogos como el que nos ha traído hasta aquí. Concretamente, el uso más antiguo del Pensé Que se suscita en una Genealogía de la Necedad del primer tercio del siglo Xvi, que debió de ser bastante conocida. ${ }^{13} \mathrm{~A}$ partir de ella, el linaje se expande rápidamente y se imbrica con una segunda familia de textos, cuya primera muestra es la difundidísima interpretación de Pérez de Moya, decisiva para el caso que aquí nos trae. Dejemos por ahora el texto primigenio para centrarnos en este autor. Es incuestionable que nos encontramos ante un precedente directo del emblema que venimos analizando pues nos hallamos frente al autor mejor representado en la biblioteca de Alonso de Barros, donde consta la Filosofía secreta (Dadson 1987: 44, núm.

"corredera». Con connotaciones muy diferentes, el vocablo "asnilla» se refiere en albañilería a la «pieza de madera sostenida por dos pies derechos para que descanse, y se mantenga en ella el edificio que amenaza ruina» (DLE).

13. La atención crítica que ese opúsculo ha recibido no se debe a su naturaleza o a su calidad, sino al interés de los estudiosos por determinar si la Genealogía de los Modorros que en 1852 incorporó Fernández Guerra a las Invectivas contra los necios en su edición de las obras de Quevedo y que Astrana asevera que se trata de un texto de juventud, puede o no puede atribuirse a su pluma y caletre. De este asunto se ha ocupado, con su conocida sabiduría, Chevalier (1974); ver además Jauralde (1983) y Schwartz (1987). Han localizado algún eslabón de esta cadena Chevalier (1974), García Valdés (1993: 122-127), Díez Fernández (1997). Sobre temas relacionados, Gili Gaya (1945), Chevalier (1973), Gómez Canseco (2011), Azaustre (2008). En todos ellos se encontrarán los detalles acerca de la localización de los textos y algún ensayo de filiación. También se esclarecen los vínculos entre Origen y difinición de la necedad, este sí de Quevedo, y el «Arancel de necedades», de Mateo Alemán, cuyas relaciones con el Galateo español puso de manifiesto Celina Sabor de Cortázar (1962), y no deben obviarse en el contexto cortesano que intentamos reconstruir. Los géneros satíricos se entrecruzan. Aunque no menciona el Pensé Que, guarda relación con el linaje de la Necedad el Hospital de necios de Luis Hurtado de Toledo, obra de entre 1565 y 1576, según los datos que presenta Jimena Gamba (2013), contenida en el Ms. 107 de la biblioteca de la Universidad de Santiago, datado en 1582. Se trata de un texto alegórico de carácter satírico y moral donde figuran varios de los integrantes de la estirpe (Gamba 2013: 76-80 y 979; vv. 1306-1330). Recuérdese el pretexto para el «Arancel de necedades", que culmina asegurando que como los sanos son pocos y los enfermos demasiados, «acordose que trocasen las estancias, y así es ya todo el mundo enfermería» (Alemán 2012: 614). El Hospital de necios es un precedente de Alemán — y de Quevedo- en algunos puntos (v. gr. vv. 397$400,441-445$, etc.); el texto apunta a la existencia de un antecedente en el Templo de la Necedad (vv. 1201 y ss., 1230-1240, 1276 y ss.), que pudiera ser común a los dos autores mayores, como pensaba Chevalier (1973: 140, nota 8) y a este nuevo eslabón de la cadena, que entrevera los géneros del arancel y de los linajes de burlas. Por otra parte, también cultivaron sus hospitales Cervantes o Quevedo, entre algunos otros. 
76). Juan Pérez de Moya, que se ocupa en cierto momento de esta obra «De la descendencia de los modorros", esos personajes embotados por una enfermedad soñolienta (Covarrubias), parece aproximar a las claras las relaciones de la ociosidad, la ignorancia y el Pensé Que. Merece la pena citar el capítulo completo, a pesar de su extensión, por sus repercusiones cortesanas:

Dicen que el Tiempo Perdido se casó con la Ignorancia, y hubieron un hijo, que se llamó Pensequé, el cual casó con la Juventud y tuvieron los hijos siguientes: No sabía, No pensaba, No miré en ello, Quién dijera. Quién Dijera se casó con el Descuido, y tuvieron por hijos a Bien está, Mañana se hará, Tiempo hay, Otra ocasión habrá. Tiempo hay se casó con la señora doña No Pensaba: tuvieron por hijos Descuídeme, Yo me entiendo, No me engañará nadie, Déjese de eso, Yo me lo pasaré. Yo Me Entiendo casó con la Vanidad; tuvieron por hijos: Aunque no queráis, Salir tengo con la mía, Galas quiero, No faltará. No faltará casó con Galas quiero; tuvieron por hijos: Holguémonos y la Desdicha, la cual se casó con Poco seso, y tuvieron por hijos a Bueno está eso, Qué le va a él, Paréceme a mí, No es posible, No me digas más, Una muerte debo a Dios, Salir tengo con la mía, Ello se dirá, Verlo heis, A voluntad determinada escusado es el consejo, Aunque me maten, Diga quien dijere, Preso por mil, preso por mil y quinientos, Qué se me da a mí, Nadie murió de hambre, No son lanzadas, que dineros son. Enviudó Galas quiero, y casó segunda vez con la Necedad; y gastado todo su patrimonio, dijo el uno al otro: Tened paciencia, que a censo tomaremos dineros con que nos holguemos este año, y el otro, Dios proveerá. Y aconsejados con No faltará, lo hicieron así; y como al plazo no hubiese con qué pagar lo que debían del censo, el Engaño púsolos en la cárcel; fueron visitados por Dios hará merced. La Pobreza los llevó al hospital, donde murieron la autoridad de Galas quiero y No miré en ello. Enterráronlos con su bisabuela la Necedad; dejaron muchos hijos y nietos derramados por el mundo.

Esta ficción nos declara en lo que paran los negligentes, flojos e inconsiderados, que no tomando consejo se gobiernan por sus pareceres, teniendo cuenta con solo el día que viven, sin consideración de su fin y de lo por venir. ${ }^{14}$

14. Pérez de Moya (1995: 346-347). «De la descendencia de los modorros» (libro II, cap. 42). En las diferentes versiones aparecen alegorías como Pobreza o Qué Me Dirán (variante de Quién Dijera), que guardan conexiones complejas de ida y vuelta con el tablero de Barros. También aparece aquí y allá la Ociosidad, por ejemplo. Existe además una expresión con el sentido, algo difuso, de 'necios' y 'ociosos', que a veces se acomoda a esta tradición desde un remoto uso bíblico. Se trata de los «hombres perdidos». Hemos registrado menciones a ellos en Antonio de Guevara (Menosprecio de corte): «No hay en esta vida cosa que sea tan enemiga de la virtud, como es la ociosidad, porque de los ociosos momentos y superfluos pensamientos tienen principio los hombres perdidos»; y más adelante, sobre casos de gente perdida en la corte (Guevara 1984: 155 y 210-211, respectivamente). La fórmula es antecedente de la denominación de Lhermite y de «La descendencia de los modorros y gente perdida», que se halla en el manuscrito núm. 109 de la Biblioteca de Menéndez Pelayo (fol. 43). La variante más notable del linaje — dejando fuera a Quevedo- es, sin duda, la del gentilhombre flamenco Jehan Lhermite en El pasatiempos. Aunque no nombra a Pérez de Moya, a diferencia de otros, se vale de él en su recreación del «Linaje de los Hijos-Perdidos», y en la historia del dios Momo que lo sigue de inmediato, como en la Filosofía secreta (Pérez de Moya 1995: 347-349). Lo más curioso de este traslado es la elipsis del Pensé Que, que marcamos con cursiva: «Dicen que el Tiempo Perdido desposó a la doncella Ignorancia y que de esta unión 


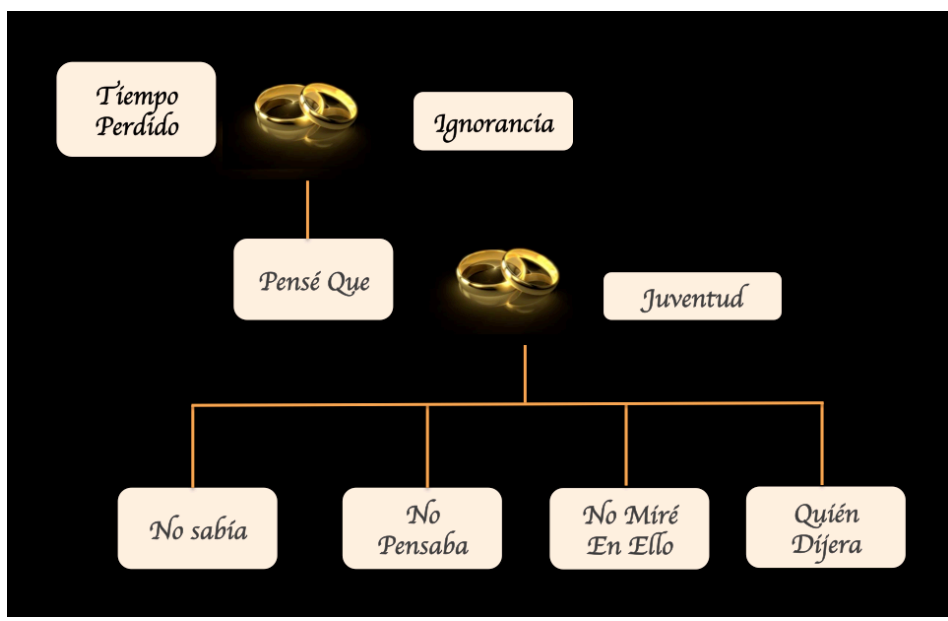

Figura 2

Cuadro genealógico.

El tono humorístico de la sátira alegórica no debe permitir que pasemos por alto la condena de una cierta forma de ociosidad característica de letrados hidalgos y más nobles estados, que viven de una economía poco o nada productiva, basada en rentas rústicas o urbanas, y son pródigos en dispendios reprobables en

salió un único hijo, cuyo nombre, costumbres y condiciones eran bastante extrañas, y de este vástago nació y ha sido engendrado a su vez este pernicioso linaje que llamamos de los Hijos Perdidos, así conocidos por hallarse extraviados y esparcidos por todo el mundo»; una rama, donde se encuentran la primera genealogía o el ejemplar editado por Díez Fernández (1997) con el título Genealogía de los Modorros, sanciona la muerte en el más allá, con el Infierno; otra edición de la Descendencia de los Modorros, que parte del Ms. 190 de la BNE, tiene un final curioso, igualmente terrible para el linaje: «La Desesperación asomó la cabeza a ver si le daban asiento y, como no se lo dieron, volviose y anduvo mendicando muchos días, en los cuales solo pudo juntar 6 maravedises, con que compró una soga y se colgó de un almena, con lo cual hizo fin el linaje de los Modorros, aunque no del todo» (Paz y Meliá 1964: 338-343). Después de pedir excusas por un encaje incoherente en sus fábulas de la Antigüedad, Juan de Piña acaba su reflexión de enmarque con estas palabras: «Una disculpa tiene este género de gente: pecar de ignorancia y no de malicia. Mas como la ignorancia no excusa la pena [...]» (Juan de Piña 1635: 26). Su inserción, a pesar de las excusas, se comprende sin dificultad pues la Epitome de Piña «resume servilmente el tratado mitográfico de Pérez de Moya» (Cristóbal 1996: 229). Quevedo hace reaparecer a Penseque en el Desposorio del Casar y la Juventud (1993: 53-55) y en el Sueño del infierno, aquí como causante de que los más de los amantes se encuentren allí (1991: 228): «Los más estaban destruidos por Penseque, según me dijo el diablo [...] No es sino que se destruyen fiándose de fabulosos semblantes, y luego dicen 'Pensé que no me obligara', 'Pensé que no me amartelara', 'Pensé que ella me diera a mí y no me quitara', 'Pensé que no estuviera otro con quien yo riñera', 'Pensé que se contentara conmigo solo', 'Pensé que me adoraba'; y así todos los amantes en el infierno están por Penseque». 
esta Nueva Babilonia que es la Corte madrileña. El final del texto, que singulariza la versión de Pérez de Moya con respecto a otras copias de esta estirpe burlesca, supone una invitación a interpretar el personaje del Pensé Que en la dirección señalada, y se conecta con principios cortesanos básicos como la prudencia y el conocimiento de uno mismo, que presiden la Filosofía cortesana. Por otra parte, no falta la dimensión áulica en un antecedente titulado El regidor o ciudadano (1578). Esta obra de Costa expone el linaje del No Pensé en el diálogo sexto, que trata "de la prudencia y como se ha de servir de ella el ciudadano o regidor», dentro del tratado primero, que versa sobre el regimiento de uno mismo.

La evolución de esta rama o de los cruces entre las dos se lee en la Censura de la locura y excelencias della, título de 1598, del licenciado Jerónimo de Mondragón, que menciona nominatim a Pérez de Moya antes de trasladar su versión. Quizá no tanto por su exégesis del Pensé Que, como por el acervo de la tradición compleja en que se inscribe, asocia el personaje a los "poltrones, perezosos y descuidados", una forma de locura, que desarrolla en el capítulo Xv (115-118):

Entran de la propria suerte en estas compañías de locos los poltrones, perezosos i descuidados, pues no puedo creer ni entiendo que nadi pueda persuadirse que los que se descuidan de sí mesmos i por pereza dexan de hazer lo que les coviene y deve hazer, por do vienen a valer menos i perderse, tengan buen entendimiento. Como se vee de ordinario en muchos, que aviéndoles dexado sus padres $\mathrm{i}$ algunos otros, haziendas harto acomodadas para vivir, i medios para passar, i aún ellos en alguna manera los an alcançado, es tanta su pereza o por mejor dezir poltronería i descuido, que dexando consumir poco a poco lo que tienen, i no queriendo trabajar, vienen los tristes a perecer de hambre. I que tal modo de gente sea loca, no hai duda en ello, porque si no lo fuera ¿̇a qué fin dixera Salomón, en el capítulo dozeno de sus Proverbios: «el que sigue la ociosidad, es loquíssimo?». Esta especie de locura i falta de juicio toca, harto bien i graciosamente, Juan Pérez de Moia en su Filosofía de los Gentiles, aunque algo más de passo que aquí, quando para mejor burlarse de los tales locos, finge una genealogía della, baxo de nombre de necedad, que es lo mesmo que falta de juizio, dando nombre a cada uno de los descendientes. Los quales nombres, son los términos o vocablos que suelen usar los tristes de quien tratamos, siempre que por pereza o descuido dexaron de hazer algo que les convenía, i les salió mal i al revés de lo que pensavan, i cuando assí mesmo, empezando [rectius: emperezando] i descuidándose, dexan de hacerlo. ${ }^{15}$

La identificación de necedad y locura por su común torpeza a la hora de tomar decisiones viene de lejos, ${ }^{16}$ pero cada una tiene su sitio (Gómez Canseco 2011). Ambas — como se ve en el pasaje citado— derivan en pereza o descuido, en dejar de hacer por lograr el propio interés.

15. Mondragón (1953: 115-116).

16. La equivalencia llega hasta el Quijote, según Guillemont y Requejo (2007: 71); ver también D’Onofrio (2018). 
Hemos visto hasta ahora cómo la exploración de la imagen no resultaba suficiente para invocar los significados que activaba Barros en un emblema cuyo nombre, por otra parte, encontraba una primera conexión directa en un linaje satírico que Pérez de Moya incluye en una obra moralizante y al que anuda con la virtud cortesana de la prudencia, aspecto en que no es el único testimonio. Pero si resulta crucial conocer la versión concreta de la descendencia del Tiempo Perdido que muy probablemente tuvo Barros en consideración, no lo es menos que antes de que la Filosofía secreta vea la luz, la historia de esta estirpe humorística, que prolonga la línea inaugurada por la Genealogía de la Necedad, hunde más sus raíces en lo popular mediante su interacción con el refranero. Así lo atestigua el comentario que Juan de Mal Lara propone en su Filosofía vulgar para uno de sus refranes. ${ }^{17}$ Este libro, si bien pudo haberlo conocido Barros, brilla por su ausencia en el conjunto de su biblioteca. Nuestro aposentador llegará a escribir un volumen de proverbios que nos lo representa como un buen conocedor y degustador de este género didáctico, al tiempo que refranes, proverbios, aforismos o apotegmas guardan relación evidente con la emblemática. ${ }^{18}$ Pues bien, Gonzalo Correas registra la voz Pensé Que y la define de manera muy próxima a las indicaciones de Barros, pero le da otro valor, muy relevante en términos curiales: "Pensé que es voz de necios. (Dícese esto a los que se excusan de sus descuidos en negocios de importancia, diciendo: 'no pensé, 'quién pensara'; porque el prudente todo ha de mirar)». Además, nos aproxima al cruce icónico de este nombre con el animal en un refrán que no deja lugar a dudas, formulado de diferentes maneras: «Penseque, asneque, burreque con sus parientes. (Añádenlo al que se excusa diciendo: 'pensé que')», "Pensé que era asneque, y era burreque», «Penseque, asneque y burreque, todos son hermanos. (Trata de asno y burro al que pierde la cosa, y se excusa con 'pensé que')».

Asumimos que Correas no inventa, sino que recoge los ecos del uso, de manera que el hecho de que su Vocabulario sea posterior al tablero resulta, a este propósito, indiferente. ${ }^{19}$ Otra cuestión sería la eventual influencia del juego

17. Sobre el refrán «Pensé que no tenía marido y comime la olla» asegura que «dos cosas hay en este refrán: la gran necedad de la mujer en el Pensé[que], el cual es hijo legítimo del Tiempo Perdido y de la Ignorancia, según traen los que saben el origen de la necedad, que es harto saber porque en el Pensé Que, pueden caer cuantas ignorancias y necedades hay en el mundo; si comenzamos desde Adán hasta nuestros tiempos todo es pensé que fuera esto y pensé que fuera lo otro [...]» (Mal Lara 2012: centuria V, núm. 43).

18. Emilio Blanco (2006) deslinda cada matiz de los conceptos de aforismo, apotegma, refrán, proverbio, y otros de la misma naturaleza breve. Aquí admitimos para su incidencia en la emblemática un parentesco de familia, sin entrar en pormenores.

19. En la misma página, da otros casos, además de recoger el de Mal de Lara: «Pensé que no tenía marido y comime la olla, y cuando le vi enmudecí, regué y embacé. (Contra los que dan excusas necias de sus descuidados)». «Pensé que no tenía marido, y comime la olla; pensé que no tenía mujer, y quemela la boca. (Bien trocada razón, y obra)». «Penseme santiguar, y quebreme el ojo, el pie». «Pensé que había hallado algo atado en el trapo» (Correas, Vocabulario [1627]: 388) «El 
de Barros sobre la evolución del concepto. Nótese que para Correas es «voz de necios», no de perezosos.

Con el sentido de necia o inadvertida aparece «la del penseque» en la Pícara Justina,$^{20}$ y ese es el uso de Gracián ${ }^{21}$ en El Criticón y el que ha perdurado en el refranero hasta nuestros días. También es, sin duda, el significado del Pensé Que en la obra de Tirso de Molina, El castigo del penseque. Del protagonista no se puede predicar la pereza o la holgazanería, aunque sí la inacción. Pero lo que le hace acreedor del castigo en pura justicia poética es su torpeza a la hora de tomar decisiones. Esta comedia palatina, como ha estudiado en profundidad Miguel $\mathrm{Zu}$ gasti, tiene por antecedente La ocasión perdida, de Lope, pues los galanes principales de ambas piezas pierden la oportunidad de mejorar de estado merced a un casamiento desigual..$^{22}$ En el caso de Rodrigo Girón, su timidez, unida a la falta de confianza en sí mismo, le impide ver el amor de la condesa de Oberisel. Diana le dicta un billete a Rodrigo, a quien ha nombrado secretario, en que le declara su amor y le propone un encuentro nocturno en el jardín. Sin embargo, Rodrigo, que no la entiende, se lo entrega a Casimiro, pretendiente de la dama y rival suyo. Tras la consumación, los penseques resultan insuficientes para restaurar la pretensión amorosa del español.

Condesa: [léase Rodrigo por Otón, hasta la agnosis final]

Otón, ¿aquí estáis? Quien tiene

entendimiento tan corto,

que para corto se quede.

pensar no es saber. (Al que dice: pensé que, le añaden: penseque, asneque, burreque, con sus parientes)»(Vocabulario [1627]: 98).

20. Pero su seguidilla dice: «Hácese la bobilla / la del penseque, / y no mira cosa / que no penetre» (López de Úbeda 1977: 393; 2011: 457).

21. Por dos veces: en El Criticón (Gracián 1993: 527-528, crisi II, 13, «La jaula de todos») y en Agudeza y arte de ingenio (Gracián 1987: 265-279, Discurso XXVII: «De las crisis irrisorias»).

22. La relación del asno echado con la Ocasión, reclinada sobre el borde exterior del recorrido del tablero de 1588, resulta llamativa, pero el texto de Barros no pide de manera precisa esa postura. Ya la advertimos en uno de los refranes de Correas: «Penseque, asneque y burreque, todos son hermanos. (Trata de asno y burro al que pierde la cosa, y se excusa con 'pensé que')». En Quien calla otorga, segunda parte del penseque motivada por la insatisfacción que produce el final para Rodrigo, dice el lacayo Chinchilla a su amo: «Fuera de que en toda España / tu crédito está perdido. / La culpa tiene tu fama, / que el castigo del penseque / y ocasión perdida pasa / de boca en boca en la corte» (vv. 630-635). Otras alusiones a la ocasión en El castigo del penseque, vv. 3077-79 y 3208-3212, con los que acaba la comedia: «El cuerdo amante escarmiente / en mí y goce la ocasión, / porque al que cual yo la pierde / le cabrá parte conmigo / del castigo del penseque». En Pérez de Moya aparecía Otra Ocasión Habrá, entre varias figuras semejantes dentro del mismo linaje. Para concluir, el insoslayable Quevedo vuelve a la genealogía en La hora de todos, donde afirma la Ocasión: «Tiene repartidas la necedad por los hombres estas infernales cláusulas: quién dijera, no pensaba; no miré en ello, no sabía; bien está; qué importa; qué va ni viene [...] Estas necedades hacen a los hombres presumidos y perezosos y descuidados. Estas son el hielo en que yo me deslizo, en estas se trastorna la rueda de mi ama y trompica la bola que la sirve de chapín [la Fortuna, claro]. Pues si los tontos me dejan pasar, ¿Qué culpa tengo yo de haber pasado?» (cit. por Schwartz 1987: 87-88). 
Don Rodrigo: Siempre hablastes por enigmas.

Condesa: Siempre el cuerdo las entiende.

¿El papel distes al Conde?

¡Agudeza fue prudente!

Don Rodrigo: Pensé que era para él.

Condesa: ¿ Hombre érades del penseque?

[Al Conde.] Vamos, venid, Conde mío.

Don Rodrigo: ¿Aqueste pago merece

mi amor?

Condesa: Así se castigan

Necedades de un penseque.

Chinchilla: :Penseque ibas a decir ahora?

Don Rodrigo: ¡Déjame! ¿Quieres

que me mate?

Chinchilla: Tú no sabes

la descendencia y parientes

del penseque, que en el mundo

tantos mentecatos tiene

dando piensos de cebada,

que es bien que a penseques piensen.

(vv. 3140-3160)

Desde este punto de vista, y considerando que el texto constituye en cierta forma una lección de cortesía amorosa, según opinión que compartimos con el editor, ${ }^{23}$ quizá convenga analizar los significados que se atribuyen al del penseque. Miguel Zugasti ha recolectado los siguientes: por su falta de arrojo, se le tilda de majadero (v. 173); sin seso (v. 191), mentecato (vv. 201 y 3158), patudo (v. 1062), necio (vv. 2310, 2574, 2748, 2757, 3008), loco (vv. 2574, 2577, 2595, 2607, 2621), arrogante (vv. 2574, 2621, 2748), ${ }^{24}$ lerdo (v. 2642), mudo (v. 2643), bobo (v. 2725), poco agudo (v. 2726), bárbaro (v. 2749), corto (vv. 3008, 3141, 3142) (cf. Zugasti 2013: 31-32). Es palmario que los semas fundamentales se dirigen a subrayar la necedad del sujeto, cuya ofuscación le impide actuar de manera correcta. No sorprende esta orientación para quien haya detectado la común raíz pare-

23. El penseque «no es una tacha moral grave, pero sí un defecto de discreción social o cortedad que don Rodrigo paga caro al perder a Diana». Y prosigue: «Pienso que, sin salirnos del plano cómico, es lícito interpretar este díptico como una lección de pedagogía amoroso-cortesana donde se nos va mostrando el variado comportamiento de los amantes» (Zugasti 2013: 37). Así interpreta Francisco de Quevedo la necedad en su Origen y difinición de la necedad, donde asegura que «es todo aquello que se hace o dice en contra o repugnando a las costumbres de cortesía o lenguaje político» (Prosa festiva completa 1993: 193).

24. La arrogancia, para lo que sigue, es una forma de error de pensamiento o necedad vana. En Alciato, la arrogancia equivocada, de fuente esópica, viene estampada como un asno sobre el que va montada la divinidad de Ceres, a cuyo paso se arrodillan los devotos. El animal cree que la genuflexión se realiza ante él (Bernat y Cull 1999: núm. 181; Esopo 1978: 122-123). 
miológica de los tres títulos, evidente en La ocasión perdida y Quien calla otorga, segunda parte del penseque y que sería extraño no aceptar en El castigo del penseque. ${ }^{25}$ Siendo obra anterior al Vocabulario de Correas alrededor de una década, nos habla de un proverbio vivo. Por lo tanto, el Pensé Que afecta a la virtud del entendimiento, la prudencia, provocando que el sujeto actúe sin compás o sea incapaz de medir sus actos por no saber discernir ni el pasado ni el presente ni el futuro. ${ }^{26}$

La necedad del animal ha quedado bien representada en la emblemática, desde Alciato, bebiendo de fuentes clásicas (Esopo, Ovidio). El asno cargado de cebada come cardos silvestres en un emblema de Sebastián de Covarrubias Orozco por un error del entendimiento, que se deja llevar por el apetito; ${ }^{27} \mathrm{o}$ en el caso del emblema de Hernando de Soto que lleva por mote "El laurel del ignorante», ${ }^{28}$ que figura a Midas con orejas de asno en estos versos: «es la ignorancia la forma, / si acaso no se limita, / que el ser de hombre al hombre quita, / como en bestia le transforma». ${ }^{29} \mathrm{La}$ animalización reduce al hombre limando su entendimiento y dando piensos de cebada.

Tanto el juego de la oca como el tablero de Barros son juegos iniciáticos, de iluminación personal, en un sentido más o menos pragmático. En última instancia, la necedad afecta también al conocimiento de uno mismo. Esta idea, central en Barros y en la literatura cortesana en general, ${ }^{30}$ preside la entrada al sendero espiriforme a modo de advertencia para el incauto pretensor que se acerca a la Corte. No en vano, los enigmas y acertijos sobre la necedad aluden con frecuencia al hecho de que quien la posee la ignora. Puede comprobarse en el que abre este estudio o en este otro de Benito Remigio, citado por Gómez Canseco (2011): «¿Qué cosa tiene la gente / que no sabe conocella / hasta que se ve sin ella / y entonces el que es prudente / procura de sí expelella?»

25. Lope de Vega sabrá mezclar con talento la estirpe satírica y el refrán popular en El alcalde mayor: «Beltrán: ¿№ era tu esposa Teodora? / Rosarda: ¡Ay, Beltán!, no sé. Beltrán: ¿`o sé? / No Sé dicen que fue nieto / de Penseque, y que Penseque / fue legítimo de Asneque» (CORDE). Chevalier facilita otra alusión suya en El mesón de la corte: «Son necios Penseque y Dizque» (Chevalier 1974: 16).

26. Así la define con claridad Saavedra Fajardo, en el comentario a la empresa 28: «Es la prudencia regla y medida de las virtudes; sin ella pasan a ser vicios. Por esto tiene su asiento en la mente, y las demás en la voluntad, porque desde allí preside todas [...] Consta esta virtud de la prudencia de muchas partes, las cuales se reducen a tres: memoria de lo pasado, inteligencia de lo presente y providencia de lo futuro» (Saavedra Fajardo 1999: 412-413; también en Bernat y Cull 1999: núm. 358). Estableció Teopompo estas tres partes, según Juan Costa (1578: fols. 60r-v).

27. Bernat y Cull (1999: núm. 182).

28. Soto (2017: 214).

29. También aparece Midas recostado con orejas de burro en un emblema de Villava (Bernat y Cull 1999: núm. 1071). Es muy común la asociación de las orejas del asno con la necedad, desde por lo menos Brandt, pero es menos conocida su adscripción a la Discordia; ver Bouza (2018: 77). El asno juzga y decide mal en otras ocasiones (Bernat y Cull 1999: núms. 183 y 184, de Mendo y Juan de Horozco y Covarrubias, respectivamente). Sobre esta cuestión de la torpeza de juicio, ver D'Onofrio (2018: 116). Acerca del proceso de animalización y capacidad de juicio, Rodríguez (2004).

30. Álvarez-Ossorio (1999: 23). 
Es momento de atar cabos. Hasta ahora solo se había abordado el estudio de la casa 55 del tablero de la Filosofía cortesana a partir del examen de la simbología asociada al animal que aparece representado. Por ese camino había notables dificultades para comprender el emblema de Alonso de Barros en toda su extensión y se obviaba el análisis del origen del nombre del Pensé Que. En este trabajo hemos demostrado que la unión de nombre y animal se suscita en el refranero, y se consolida y contamina a partir de un linaje de burlas de carácter alegórico, que hizo fortuna. Aunque las dos tradiciones confluyen en la Filosofía vulgar, la formulación explícita del refrán que nos atañe procede de Covarrubias, pero incide sobre la semántica de la necedad. La genealogía satírica, ahora con tintes moralizantes y alguna relación con el ámbito cortesano cristaliza, por su parte, en la Filosofía secreta de Pérez de Moya. Aquí, el Pensé Que es una representación determinada por sus progenitores, Ignorancia y Tiempo Perdido. Barros hace prevalecer la ociosidad, sin perder de vista que la falta de previsión del descuidado remite en último término a un error del entendimiento por falta de prudencia, con lo que eso representa en el plano cortesano.

Cualquier exploración sobre los sentidos simbólicos de la imagen, incluida la tradición emblemática, muestra una clara preferencia por el sema de la necedad, antes que por el de pereza, que no se excluye. Y ese es el sentido que va a predominar tanto en la literatura de entretenimiento como en la prosa didáctica, satírica o no. En Barros, en cambio, lo primordial es que el asno se opone a la debida diligencia al permanecer echado e inactivo, sin perder de vista su paradigmática necedad. Nada de ello es óbice a que la pereza sea ya en alguna manera un error del entendimiento; o de la voluntad. Barros, en cierto modo, es una isla, puesto que dispone las cantidades de estos ingredientes de manera diametralmente contraria a lo común. Pero en el momento de construir su imagen, todas estas fuentes fluyen y son el caldo de cultivo de este y de otros emblemas, pasados por el cedazo de la experiencia personal de nuestro autor, en algún caso, y de sus lecturas. Lo original es la aplicación política concreta del refranero, su figuración y el lugar que ocupa en el eje acción-pasividad de la condición cortesana del pretensor, donde negligencia se opone a Diligencia, una de las casas que llevan hacia la merced.

En efecto, frente al estatismo de los emblemas relacionados con la ociosidad, los medios «más usados» para eludir las mudanzas de Fortuna, como Adulación, Liberalidad o Trabajo exigen actividad. Cuando la tirada de dados lleva al pretensor a los dominios del Pensé Que, retrocederá de la casa 55 a la número 20, donde se halla la Diligencia. ${ }^{31}$ La sanción didáctica aleja al pretensor de su

31. La Diligencia está representada por un escarabajo: «Mándasele al tal descuidado que torne y haga Diligencia, mirando como la hace el escarabajo, que con más carga que fuerzas procura llevar a su cueva una bola de estiércol, como en efeto lo es todo lo que se pretende, y por ella se muestra lo mucho que en el mundo se trabaja, y el porqué. Lo cual está figurado a veinte casas 
objetivo, mas si persevera en el camino con trabajo constante, aún estará en disposición de llegar a la Palma de la Vitoria y lograr la merced. Pero esa es otra historia.

con una letra que dice: Cuanto trabaja y procura, / el mundo todo es basura» (Barros 1987: 28v29r). Esta peculiar conexión del asno con el coleóptero - y el buey, que simboliza el trabajo en Barros- se halla en Pierio Valeriano (1556: fol. 60r). De ahí parece tomarla Sebastián de Covarrubias en la entrada que le dedica al escarabajo: «Dicen que en cierto tiempo del ańo, tomando por materia el excremento del buey o jumento, forma cierta pelotilla redonda en que ya parece imitar la forma del mundo. Y luego de Oriente la va revolviendo hacia Occidente, vuelto él al revés, rempujándola con los pies traseros, que parece habernos querido dar a entender en esto el movimiento propio del firmamento y el de los planetas ser de Occidente a Oriente, no embargante que del primer móvil sean llevados del movimiento contrario de Oriente a Occidente» (Covarrubias) En todo caso, es profundamente seductora la vinculación del esquema áulico con el de contemptu mundi. 


\section{Bibliografía}

Alemán, Mateo, Guzmán de Alfarache, ed. de Luis Gómez Canseco, Madrid, 2012, RAE.

Álvarez-Ossorio, Antonio, "La discreción del cortesano», Edad de oro, 28 (1999), 9-45.

Apuleyo, El asno de oro, trad. de Diego López de Cortegana, Madrid, Editorial Libra, 1970.

Azaustre, Antonio, «Transmisión textual y edición de Origen y difinición de la necedad, de Francisco de Quevedo", A mi dizen quantos amigos ey, Homenaxe ao profesor Xosé Luis Couceiro, Universidade de Santiago de Compostela, 2008, 57-66.

Barros, Alonso de, Filosofía cortesana [Madrid, Pedro Madrigal, 1587], ed. Trevor J. Dadson, Madrid, Comunidad de Madrid, 1987.

—, Proverbios morales, Madrid, Luis Sánchez, 1598.

Bernat Vistarini, Antonio y Cull, John, Enciclopedia de emblemas españoles ilustrados, Madrid, Akal, 1999.

Blanco, Emilio, "Aforismos políticos contra sentencias morales», Res publica litterarum. Documentos de trabajo del grupo de investigación "Nomos", Universidad Carlos III de Madrid, 2006, 1-29.

BouzA, Fernando, Imagen y propaganda. Capitulos de historia cultural del reinado de Felipe II, Madrid, Akal, 2018.

Cervantes de salazar, Francisco, Apólogo de la Ociosidad y el Trabajo de Luis Mexía, glosado y moralizado por Francisco Cervantes de Salazar, ed. de Consolación Baranda, Salamanca, Ediciones Universidad de Salamanca, 2012.

Chevalier, Maxime, "Guzmán de Alfarache en 1605: Mateo Alemán frente a su público", Anuario de Letras [México], 11 (1973), 125-147.

—, "Genealogía de la necedad», Les langues neolatines, 209 (1974), 12-18.

Collar de CÁceres, Fernando, «El tablero italiano de la Filosofía cortesana de Alonso de Barros (1588); la carrera de un hombre de corte», Anuario del Departamento de Historia y Teoría del Arte, 21 (2009), 81-104.

Corde (Corpus Diacrónico del Español - Real Academia Española) <www.rae. es> [fecha de consulta: 1-1-2019].

Correas, Gonzalo, Vocabulario de refranes y frases proverbiales y otras fórmulas comunes de la lengua castellana en que van todos los impresos antes y otra gran copia que juntó el maestro Gonzalo Correas [1627], Madrid, RAE, Establecimiento tipográfico de Jaime Ratés, 1906.

Costa, Juan, El regidor o ciudadano, Salamanca, Antonio de Lorenzana, 1578.

Covarrubias Orozco, Sebastián de, Tesoro de la lengua castellana, o española, Madrid, por Melchor Sánchez, a costa de Gabriel León, 1674; Alicante, Biblioteca Virtual Miguel de Cervantes; Madrid, Biblioteca Nacional, 2006 $<$ http://www.cervantesvirtual.com/obra-visor/del-origen-y-principio-de-lalengua-castellana-o-romance-que-oy-se-vsa-en-espana-compuesto-por-el--0/ 
html/00918410-82b2-11df-acc7-002185ce6064_991.html> [fecha de consulta: 1-1-2019].

Cristóbal, Vicente, «Un oscuro manual hispano de mitología: la Epítome de las fábulas de la Antigüedad de Juan de Piña», Cuadernos de Filología Clásica, 10 (1996), 229-236.

Dadson, Trevor J., «La biblioteca de Alonso de Barros, autor de los Proverbios morales», Bulletin Hispanique, 89 (1987), 27-53.

—, Libros, lectores y lecturas, Arco/Libros, Madrid, 1998.

Díez Fernández, Ignacio, «Una premática, una genealogía y dos textos de Quevedo", La Perinola: Revista de investigación quevediana, 1 (1997), 125-150.

D’Onofrio, Julia, «De las orejas a la cola. Deleite, parodia y autoconocimiento en las representaciones simbólicas del asno y el mono en el Quijote (II, 2428)», Anales Cervantinos, 50 (2018), 105-135. <https://doi.org/10.3989/anacervantinos.2018.004>

Egido, Aurora, "Linajes de burlas en el Siglo de Oro», Studia Aurea, Actas del III, Congreso de la AISO, I, Plenarias. General. Poesía, I. Arellano, M. C. Pinillos, F. Serralta, M. Vitse (eds.), Pamplona, GRISO-LEMSO, 1996, 19-50.

ELIAS, Norbert, El proceso de la civilización. Investigaciones sociogenéticas y psicogenéticas, México, FCE, 1988.

Escobar Borrego, Francisco Javier, «Diego López de Cortegana traductor del Asinus Aureus: el cuento de Psique y Cupido", Cuadernos de Filología Clásica. Estudios Latinos, 22.1 (2002), 193-209.

—, «La recepción de Apuleyo en el humanismo sevillano renancentista: versiones vernáculas y neolatinas del mito de Psique», La mythologie classique dans la littérature néo-latine. En hommage à Geneviève et Guy Demerson, ClermontFerrand, Universitè Blaise Pascal, Collection ERGA. Littératures et représentations de l'Antiquité et du Moyen Âge, Virginie Lerroux (coord.), 2011, 95-107.

Esopo, Fábulas de Esopo, Vida de Esopo, Fábulas de Babrio, trad. de P. Bádenas de la Peña y J. López Facal, Madrid, Gredos, 1978.

Fernández Guerra, Aureliano, Obras de Don Francisco de Quevedo Villegas. Tomo primero / de Don Francisco de Quevedo Villegas; colección completa, corregida, ordenada e ilustrada por D. Aureliano Fernández-Guerra y Orbe, Alicante, Biblioteca Virtual Miguel de Cervantes, 2007.

Gamba Corradine, Jimena, Escrituras, hurtos y reelaboraciones de Luis Hurtado de Toledo (1523-1590): Edición de su obra literaria y estudio de su obra impresa, Universidad de Salamanca, 2013 (Tesis doctoral) <https:/gredos.usal.es/ jspui/bitstream/10366/122978/1/DLEH_Gambacorradine_escriturashurtosreelaboracionesluishurtadodetoledo.pdf> [fecha de consulta: 1-1-2019].

GIL, Juan, «Apuleyo y Delicado: el influjo de El Asno de Oro en La Lozana Andaluza", Habis, 17 (1987), 209-219.

—, «Apuleyo en la Sevilla renacentista», Habis, 23 (1992), 297-306.

Gili GaYa, Samuel, «El Guzmán de Alfarache y las premáticas y aranceles generales», Boletín de la Biblioteca de Menéndez Pelayo, 21 (1945), 436-442. 
Gómez Canseco, Luis, "Tontos a manta. Catálogos de necios en el siglo de oro", Humor i literatura: ridentem dicere verum, Germà Colón Domènech y Santiago Fortuño Llorens (eds.), Universitat Jaume I, Servicio de publicaciones, 2011, 125-142.

Gracián, Baltasar, El Criticón, ed. Santos Alonso, Madrid, Cátedra, 1993.

—, Agudeza y arte de ingenio, ed. Evaristo Correa Calderón, Madrid, Castalia, 1987.

Gracián Dantisco, Lucas, Galateo español, ed. Margherita Morreale, Madrid, CSIC, 1968.

Guevara, Antonio de, Menosprecio de corte y alabanza de aldea, ed. de Asunción Rallo, Madrid, Cátedra, 1984.

Guillemont, Michèle y Marie-Blanche Requejo Carrió, «De asnos y rebuznos. Ambigüedad y modernidad de un diálogo», Criticón, 101 (2007), 57 87.

Hurtado de Toledo, Luis, Hospital de necios hecho por uno de ellos que sanó por miraglo, ed. de Valentina Nider y Ramón Valdés, Mauro Baroni editore, Viareggio-Lucca, 2000.

Jauralde, Pablo, "Obrillas festivas de Quevedo: estado actual de la cuestión", Serta Philologica F. Lázaro Carreter, Madrid, Cátedra, 1983, II, 275-284.

Lhermite, Jehan, El pasatiempos. Memorias de un gentilhombre flamenco en la corte de Felipe II y Felipe III, ed. de J. Sáenz de Miera, Aranjuez, Docecalles, 2005.

López de Úbeda, Francisco, Pícara Justina, ed. Antonio Rey, Madrid, Editora Nacional, 1977.

—, Pícara Justina, ed. Luc Torres, Madrid, Clasicos Castalia, 2010.

Lozano Pérez Ramajo, Manuel, El asno ilustrado, o sea, La apología del asno, Madrid, Imprenta nacional, 1837.

Lucero SÁnchez, Ernesto, «La idea del Trabajo en la Filosofía cortesana de Alonso de Barros», Hipogrifo. Revista de literatura y cultura del Siglo de Oro, $7.2(2019)$.

Mal Lara, Juan de, Filosofía Vulgar [Sevilla, Hernando díaz, 1568], ed. facsímil de José J. Labrador y Ralph A. Difranco, México, Frente de Afirmación Hispanista, 2012.

Mondragón, Jerónimo de, Censura de la locura humana y excelencias della, [Lérida, Antonio de Robles, 1598], ed. de Antonio Vilanova, Barcelona, Selecciones bibliófilas, 1953.

Nider, Valentina, «De los Hospitales de amor al Hospital de necios (de Boscán a Hurtado de Toledo)", Actas del V Congreso de AISO, 2001, 926-933.

Paz y Meliá, Antonio, Sales Españolas o Agudezas del Ingenio nacional, Madrid, Impresión de M. Tello, 1890, Madrid, BAE, 176, 1964, 338-343 <https:// archive.org/details/salesespaolas01pazyuoft/page/n8> [fecha de consulta: 18-08-2018].

—, Sales españolas, BAE, 176, Madrid, Atlas, 1964, 225-230.

Pérez de Moya, Juan, Philosofía secreta [1585], ed. Carlos Clavería, Madrid, Cátedra, 1995. 
PIÑA, Juan de, Epitome de las fábulas de la Antigüedad, Madrid, en la Imprenta del Reyno, 1635, Universidad Complutense, <http://alfama.sim.ucm.es/ dioscorides/consulta_libro.asp?ref=B19777863\&idioma $=0>[$ fecha de consulta: $12-08-2018]$.

Quevedo, Francisco de, Prosa festiva completa, ed. de Celsa Carmen García Valdés, Cátedra, Madrid, 1993.

—, Obras jocosas, M. E. Editores, 1993.

—, Sueños, ed. de Ignacio Arellano, Madrid, Cátedra, 1991.

-, Obras completas. Obras en prosa. Obras en verso, ed. de Luis Astrana Marín, Madrid, Aguilar, 1941 (1932).

-, Obras de don Francisco de Quevedo y Villegas, ed. de Fernández Guerra, BAE, tomo XXIII, Madrid, Atlas, 1946.

Real Academia Española, <www.rae.es> [fecha de consulta: 1-1-2019].

—, Diccionario de la lengua castellana, I (A-B), Madrid, Joaquín Ibarra, 1770.

- Diccionario de la lengua castellana, reducido a un solo tomo para su más fácil uso, Madrid, Joaquín Ibarra, 1773, 2a ed. Reproducción digital, Alicante, Biblioteca virtual Miguel de Cervantes, 2008.

Ripa, Cesare, Iconología, Madrid, Akal, 1987.

Rodríguez, Alberto, «Del episodio del rebuzno al gobierno de Sancho: la evolución simbólica de la imagen del burro", Peregrinamente peregrinos. Actas del V Congreso Internacional de la Asociación de Cervantistas, A. Villar Lecumberri (ed.), Lisboa, Fundaçao Calouste Gulbenkian, 2004, 1675-1686.

SaAvedra Fajardo, Diego, Empresas politicas, ed. de Sagrario López Poza, Madrid, Cátedra, 1999.

Sabor de Cortázar, Celina, «El Galateo español y su rastro en el Arancel de necedades», Hispanic Review, 30.4 (1962), 317-321.

Schwartz, Lia, «Texto anónimo y texto satírico: sobre las invectivas contra los necios de Quevedo", Filología, 22.1 (1987), 71-88.

Soto, Hernando de, Emblemas moralizadas, ed. de José Julio García Arranz y Nieves Pena Sueiro, Madrid, José J. de Olañeta, 2017.

Tirso de Molina, El castigo del penseque. Quien calla otorga, ed. Miguel Zugasti, Madrid, Cátedra, 2013.

Valeriano, Pierio, Hieroglyphica, sive, De sacris Aegyptiorvm literis commentarii, Basilea, 1556 01-01-2019 <https://archive.org/details/desacrisaegyptio00vale> [fecha de consulta: 1-01-2019].

Zugasti, Miguel, «La ocasión perdida, antecedente necesario de El castigo del penseque de Tirso de Molina», Tirso de Molina: textos e intertextos. Actas del Congreso Internacional organizado por el GRISO y la Universidad de Parma, Laura Dolfi y Eva Galar (eds.), Madrid, Pamplona, Instituto de Estudios Tirsianos, 2001, 11-38. 